\title{
STAKEHOLDERS NO SETOR HOTELEIRO - IDENTIFICAÇÃO E CARACTERIZAÇÃO: UM ESTUDO NA REDE HOTELEIRA DE FOZ DO IGUAÇU-PR
}

\author{
STAKEHOLDERS IN THE HOTEL SECTO - IDENTIFICATION AND CHARACTERIZATION: A \\ STUDY IN THE HOTEL CHAIN OF FOZ DO IGUAÇU-PR
}

Nayani Pereira Dias

Universidade Estadual do Oeste do Paraná, PR, Brasil, nayani_pd@hotmail.com

Vinicius Abílio Martins

Universidade Estadual do Oeste do Paraná, PR, Brasil, vinicius.martins@unioeste.br

José Antonio Cescon

Universidade Estadual do Oeste do Paraná, PR, Brasil, cescon@cescon.adm.br

DOI: http://dx.doi.org/10.31512/gesto.v9i2.275

Recebido em: 06/11/2020

Aceito em: 15/01/2021

Resumo: A Teoria dos Stakeholders dispóe que se considera relevante qualquer ator que possa influenciar ou ser influenciado pelas açôes de uma empresa, e assim sendo, as empresas precisam estar atentas às influências sofridas para tomar as atitudes apropriadas. Ter conhecimento de quais são os Stakeholders que afetam as organizaçóes, pode exercer grande influência nos objetivos e na forma como elas administram seus recursos. O setor hoteleiro possui grande representatividade na economia nacional e, atividades ligadas ao turismo, comércio e eventos são grandes responsáveis pela movimentação do setor. A cidade em questão neste estudo, localiza-se em tríplice fronteira, tem por base da economia o turismo, comércio e serviços e seus atrativos movimentam fortemente a atividade hoteleira no município. Diante do exposto, o estudo tem por objetivo identificar quais são os Stakeholders no setor hoteleiro em Foz do Iguaçu-PR, classificá-los e indicar qual a relevância para a atividade. Os dados foram extraídos por meio de entrevistas realizadas diretamente com os representantes das organizaçóes. Os resultados apontaram a presença de vinte e dois Stakeholders significativos para o funcionamento do setor hoteleiro na cidade de Foz do Iguaçu-PR.

Palavras-chave: Teoria dos Stakeholders. Classificação dos Stakeholders. Setor hoteleiro.

Abstract: The Stakeholder Theory states that any actor who can influence or to be influenced by the actions of a company is considered relevant, and therefore, companies need to be aware of the influences suffered to take the appropriate actions. Having knowledge of the Stakeholders that affect organizations, can have a great influence on the objectives and the way they manage their resources. The hotel sector has great representativeness in the national economy, and activities related to tourism, trade and events are largely responsible for the movement of the sector. The city in question in this study is located on triple frontier, based on the economy tourism, commerce and services, and its attractions strongly move the hotel activity in the municipality. Given the above, the study aims to identify who are the Stakeholders in the hotel sector in Foz do Iguaçu-PR, classify them and indicate what is the relevance for the activity. The data were extracted through interviews conducted directly with representatives of the organizations. The results showed the presence of twenty-two significant Stakeholders for the operation of the hotel sector in the city of Foz do Iguaçu-PR.

Keywords: Stakeholder theory. Stakeholder classification. Hotel sector. 


\section{Introdução}

A partir do momento em que as empresas entram em processo de evolução e maior complexidade, passa-se a notar ainda mais os impactos do ambiente externo em suas operaçóes, em consequência os gestores necessitam desenvolver maneiras para gerir essas influências (MARTINS; ENSSLIN, 2020; MARTINS; ENSSLIN; DUTRA, 2018). Entende-se que, o ambiente externo é composto por grupos que interagem com as organizaçóes, exercendo uma troca mútua de interesses, podendo afetar ou ser afetado pelas organizaçôes (MATOS, et al, 2020; FABRIS; FISCHER; SEHEM, 2015).

É nesse contexto de mudança organizacional que a Teoria dos Stakeholders começa a ganhar força nos processos de identificaçáo e relacionamentos com as partes interessadas nas organizaçóes (CINTRA, 2013). Isso exige que os administradores entendam melhor a individualidade e aspectos desses grupos de interesse, denominados Stakeholders.

Um dos principais autores a difundir a teoria foi Freeman, que contribuiu para o conhecimento com sua obra "Gestão Estratégica: uma abordagem das partes interessadas" (tradução livre), publicada no ano de 1984, cujo relato apresenta que a principal ênfase da Teoria dos Stakeholders está na eficácia das organizaçóes, onde o foco não é satisfazer somente os acionistas, mas também aqueles que possuem algum vínculo com a organização (COSTA, et al., 2012). A Teoria dos Stakeholders salienta que é necessária a participação dos Stakeholders para uma empresa se desenvolver, e que as organizaçóes devem buscar atender aos interesses de todas as partes interessadas, ao invés de exclusivamente maximizar os lucros para acionistas (WANG, 2018).

O conhecimento de quais são os Stakeholders que afetam as organizações, pode auxiliar as mesmas a entenderem o meio em que atuam e a realizar um melhor gerenciamento dos recursos que dispóe. Desta forma, auxilia na administração de setores que têm o potencial de exercer grande impacto na economia, como é o caso do setor hoteleiro, em determinadas circunstâncias.

O setor hoteleiro tem grande representatividade na economia nacional. Segundo dados da ABIH Associação Brasileira da Indústria de Hotéis, o setor é responsável por mais de 1.350 .000 empregos diretos e 675.000 empregos indiretos (ABIH, 2019).

Com um mercado amplo, as entidades, tanto no setor hoteleiro quanto nos demais setores, necessitam que sua gerência tenha conhecimento não só dos próprios interesses como também dos interesses dos atores envolvidos em sua operação, possibilitando gerenciar estrategicamente tais aspectos e maximizar a criação de valor para os Stakeholders (SCHEMBRI, et al., 2019). Fatores internos e externos influenciam no gerenciamento das organizaçóes, cabendo à gestão relacionar qual o grau de influência sofrida ou empregada em cada Stakeholder, para racionalizar a alocação de recursos e assim obterem resultados melhores para ambos (WILLIAMSOM, 1973).

A cidade de Foz do Iguaçu-PR localiza-se em tríplice fronteira, onde faz divisa com a cidade argentina de Puerto Iguazú e com a cidade paraguaia de Ciudad del Este (PMFI, 2019a). Tem por base da economia o turismo, comércio e serviços, além de contar com uma infinidade de opçóes para passeios, lazer e gastronomia (PMFI, 2019a). A cidade dispóe de diversos atrativos turísticos, dentre os quais se destacam dois ícones, as Cataratas do Iguaçu e a Hidrelétrica de Itaipu (PMFI, 2019b). Por atrair grande 
público, seja por turismo, comércio, eventos, a passagem de pessoas pela cidade movimenta fortemente a atividade hoteleira no município.

Em virtude da relevância e magnitude da atividade hoteleira na cidade de Foz do Iguaçu-PR, somando-se a dimensão que o ramo representa para a economia da cidade, percebe-se a necessidade de identificar os principais interessados no setor e consequentemente nas atividades do ramo, dado que as organizaçóes envolvidas possuem a oportunidade de obter benefícios decorrentes de tal identificação.

Diante do exposto, o problema desta pesquisa se define em: Quais os Stakeholders do setor hoteleiro em Foz do Iguaçu-PR, considerados mais significativos para a atividade?

Em função disso, o estudo tem por objetivo identificar quais são os Stakeholders no setor hoteleiro em Foz do Iguaçu-PR, classificá-los e indicar qual a relevância para a atividade.

O contexto em que o trabalho se insere evidencia que o ramo hoteleiro é de grande importância para a cidade. Trata-se de um estudo em uma cidade com atividade turística expressiva, situado em regiáo de tríplice fronteira. Ainda, acentua-se o fato do setor ser responsável por movimentar uma parcela considerável da economia do município.

Saber quais são e compreender a atuação dos Stakeholders implica em consequentemente saber como gerenciá-los, e assim cumprir também com sua responsabilidade social, agregando benefícios para a comunidade como um todo. Neste sentido, conhecer quem são as partes interessadas e qual a sua influência em organizaçóes do ramo hoteleiro, denota a importância para a economia não só diretamente das empresas, mas para todos os envolvidos inclusive a sociedade de modo geral.

\section{Referencial Teórico}

\subsection{Stakeholder}

O termo Stakeholder foi inicialmente utilizado em um memorando interno do Stanford Research Institute, no ano de 1963. Na ocasião, o termo fazia referência a grupos cuja ausência de apoio acarretaria o fim da existência de uma organização (SERAFIM; ALPERSTEDT, 2012). O conceito de Stakeholder mais conhecido e tradicional foi formulado por Edward Freeman, em seu livro Strategic management: a Stakeholder approach, em 1984 (MELO; RÉGIS, 2012).

O termo Stakeholder também teria sua origem no termo Stockholder (acionista), ampliando o foco da organização, que anteriormente era satisfazer o acionista passando a ser então satisfazer seus públicos de interesse estratégicos, como clientes, funcionários, parceiros, concorrentes e a comunidade (ROCHA; GOLDSCHMIDT, 2010). Deste modo, entende-se que Stakeholders não se limitam ao seleto grupo de acionistas interessados, denominados stockholders, mas englobam um conjunto maior (LUGOBONI; GOTO, 2018).

Stakeholders podem ser definidos como pessoas ou grupos que requerem posse, direitos ou interesses em uma organização, seja em suas atividades presentes, passadas ou futuras (HOFF, 2008). Considerando que os Stakeholders podem tanto afetar quanto serem afetados pela organização, acabam por contribuir no desempenho da mesma, como na geração de lucros e continuidade (RIBEIRO, 2016). Por possuir 
interesses semelhantes, podem ser classificados como pertencentes ao mesmo grupo, como fornecedores, empregados, clientes, acionistas (HOFF, 2008). O posicionamento de exigência de direitos e interesses surge em decorrência de transaçóes com a organizaçáo ou de açóes empreendidas por ela, podendo ser legais ou morais, individuais ou coletivas (HOFF, 2008).

De acordo com Barbieri e Cajazeira (2009, p. 26-27) Stakeholder "é alguém que tem direitos em um negócio ou empresa ou que nela participa ativamente ou está envolvido de alguma forma”. A emergência desse termo em áreas como planejamento corporativo, teoria organizacional, teoria dos sistemas, responsabilidade social e estratégia empresarial, se deve à certificação de que os interesses dos proprietários não são os únicos que devem ser considerados no gerenciamento das organizaçôes (BARBIERI; CAJAZEIRA, 2009).

Segundo Hoff (2008) o termo Stakeholder vai além de ser simplesmente sinônimo das terminologias usadas para identificar os agentes que se relacionam com as organizaçôes, ou seja, o termo engloba também perspectivas importantes que auxiliam na compreensáo quanto ao desenvolvimento do relacionamento destes com as organizaçôes no decorrer do tempo e vice-versa.

As definiçôes de Stakeholders consideram qualquer grupo de interesse nas organizaçóes e não apenas aqueles diretamente relacionados e envolvidos nas atividades da empresa, como empregados, clientes, fornecedores, investidores, sindicatos, empreiteiros e autoridades governamentais (BARBIERI; CAJAZEIRA, 2009). Tais grupos já são incluídos na gestão convencional perante a interesses da empresa, pois são fundamentais para o bom resultado das suas atividades. Assim, considerar apenas esses grupos seria uma forma restrita de abordar o tema (BARBIERI; CAJAZEIRA, 2009).

\subsection{Teoria dos Stakeholders}

Anterior aos debates sobre a Teoria dos Stakeholders, as principais teorias da organização defendiam que as empresas tinham como principal função a maximização do retorno sobre investimento dos proprietários da companhia (TEIXEIRA; MAZZON, 2000). A partir desta proposição a "Teoria dos Shareholders" baseia-se na premissa de que as empresas existem com a finalidade de gerar resultados financeiros, lucros, com o objetivo de recompensar aos acionistas e proprietários, assegurando que a organização continue operando (SANTOS, 2006).

Santos (2006), pondera que durante décadas, cabia à empresa atender não mais que as expectativas dos acionistas, sendo eles os principais interessados, e o mais importante Stakeholder. Para o autor, a responsabilidade social era um compromisso a encargo da sociedade e não uma incumbência das empresas, ou seja, não era responsabilidade das empresas satisfazer a todas as expectativas.

A Teoria dos Shareholders dispóe que os Stakeholders são considerados na medida em que influenciam os resultados, os lucros, taxa de crescimento dentre outros (CAMPOS, 2006). Neste sentido, a organização não tem como objetivo primário atender aos Stakeholders em seu conjunto, mas sim a grupos de Stakeholders em particular, os acionistas. Dessa forma, os demais Stakeholders são apenas um meio para atender a um grupo específico e não um fim em si (CAMPOS, 2006).

Ainda conforme Santos (2006), a ideia de que a empresa possui responsabilidades sociais para além da geração de produtos e serviços, pode ser considerada um conceito contraditório com relação 
ao caráter e natureza de uma economia livre. Em contrapartida, as organizaçôes são instituiçóes sociais, e atingem a comunidade de diversas maneiras, tal como geração de empregos e desenvolvimento da economia, e assim sendo, considera que as organizaçóes devem além de ter como objetivo a maximizaçáo dos ganhos, também serem responsáveis em suas atividades para que estejam em conformidade com as expectativas da sociedade.

Tal teoria começou a ser contestada por autores que consideravam que havia a capacidade de a organização construir relaçôes dinâmicas e consistentes com os diversos grupos aos quais mantinha contato, grupos estes nomeados de Stakeholders (SANTOS, 2006). Partindo deste contexto, dá-se início a discussóes direcionadas a Teoria dos Stakeholders, em que além da busca pelo alcance de objetivos de grupos específicos, visando aos resultados, nota-se a importância de relacionar os diversos interesses envolvidos em uma organização, envolvendo não só ela, mas também as partes interessadas.

\subsection{Conceitos e Abordagens da Teoria dos Stakeholders}

Também conhecida como Teoria das Partes Interessadas, a Teoria dos Stakeholders tomou grande impulso com as abordagens de gestão fundamentadas na visão sistêmica, na medida em que ressalta o ambiente das organizações e o entende constituído de diferentes segmentos da sociedade (BARBIERI; CAJAZEIRA, 2009). Esses diferentes segmentos da sociedade possuem expectativas e interesses próprios, sendo assim, os gestores das empresas necessitam identificá-los para lidar com eles da melhor forma (BARBIERI; CAJAZEIRA, 2009).

Em uma visão mais ampla, na Teoria dos Stakeholders considera-se relevante qualquer ator que possa influenciar ou ser influenciado pelas açóes da empresa, deste modo, a organizaçáo deveria atentar-se a este fato para a definição de suas açóes, considerando a presença de todos os atores envolvidos. Logo, para manter-se em um ambiente repleto de Stakeholders, a organização necessita estar atenta a influência sofrida e tomar açóes adequadas (MEHERISHI; NARAYANA; RANJANI, 2019).

O relacionamento entre a empresa e os Stakeholders deve se basear em confiança e reciprocidade, que leva ao compartilhamento de informaçóes entre ambos, permitindo a eficiência na alocaçáo de recursos e a geração de vantagens competitivas no mercado (ORTEGA et al., 2016). Sendo assim, atender aos interesses dos Stakeholders tem o potencial de gerar vantagens competitivas (ORTEGA et al., 2016). Desta forma, se atentar aos interesses dos Stakeholders pode reduzir as chances de conflitos (NACITI, 2019).

A Teoria dos Stakeholders pode ser apresentada e utilizada sob três aspectos: Descritiva, Instrumental e Normativa. Como descritiva a mesma apresenta um modelo em que descreve uma corporaçáo, podendo explicar as características e comportamentos particulares da organização, como a natureza das empresas, qual o pensamento dos trabalhadores a respeito da administração e como algumas empresas realmente são administradas (BARBIERI; CAJAZEIRA, 2009).

Enquanto instrumental, ela estabelece uma estrutura analítica para que se possa analisar as ligaçóes entre a prática do gerenciamento dos Stakeholders e a obtenção de diversos objetivos da performance corporativa (GOMES; ALMEIDA, 2017). Usado comumente para relacionar detalhadamente eventos específicos entre causa (gerenciamento das partes interessadas) e efeito (desempenho da organização) 
(HOURNEAUX JUNIOR et al., 2014). Visa também identificar possíveis falhas nas ligaçóes entre a gestão de Stakeholders e o alcance de objetivos (BARBIERI; CAJAZEIRA, 2009).

Por fim, é normativa dado que define padrôes de comportamento e ação das organizaçóes no que diz respeito ao gerenciamento das relaçóes com os Stakeholders, tendo em vista a melhora no desempenho final da organização (HOFF, 2008). Neste sentido, a Teoria dos Stakeholders busca interpretar, realizar uma análise das atribuiçóes das empresas e disponibilizar diretrizes morais e filosóficas para seus procedimentos de administração e gestão (BARBIERI; CAJAZEIRA, 2009).

Em síntese, o uso descritivo se dá quando a organização utiliza o modelo para representar e compreender suas relaçóes nos ambientes externo e interno, o uso instrumental quando se utiliza como ferramenta de gestão, e o uso normativo ocorre quando a organização reconhece os interesses de todos os Stakeholders (GATTAI; SIQUEIRA; FISCHER, 2013).

Para Donaldson e Preston (1995) a Teoria dos Stakeholders também pode ser considerada gerencial, no sentido amplo do termo. A teoria não se refere apenas a situaçóes existentes ou pressupóe relaçôes entre causa e efeito, também recomenda atitudes, estruturas e práticas que, quando tomadas em conjunto, formam o gerenciamento dos Stakeholders. Para os autores, a Teoria dos Stakeholders se difere de outras teorias da firma de modo fundamental, uma vez que ela objetiva tanto esclarecer quanto orientar a estrutura e operação da organização, fazendo com que ela seja vista como uma instituição pela qual, inúmeros participantes alcançam múltiplos propósitos, nem sempre totalmente congruentes.

Mitchell, Agle e Wood (1997), trazem a proposição de um modelo que se sustenta em três dimensōes, sendo elas: 1) o poder dos Stakeholders para influenciar a organização, 2) a urgência da pretensão do Stakeholder para com a organização, e 3) a legitimidade no relacionamento do Stakeholder com a organização.

Com base na percepção de Mitchell, Agle e Wood (1997), Gomes (2006) descreve as três dimensões. Na dimensão poder, sugere-se que seja resultado provavelmente de três dimensôes contextuais: poder normativo, poder coercitivo e poder utilitário. Em urgência, justifica que a mesma possui vários significados, mas com relação a gestão de Stakeholders pode ser entendida como resultado da sensibilidade e criticidade do tempo, ou seja, a urgência se dá para um Stakeholder no momento em que suas demandas devem ser tratadas em um curto espaço de tempo, caso contrário a organização estará com um sério problema. Quanto à legalidade, nota-se que, por vezes, pode ocorrer de haver um interessado com uma demanda que náo seja legal ou moral. Dessa forma sugere que apenas atores com legitimidade sejam considerados Stakeholders. Para isso define legitimidade como uma percepção generalizada de que as açôes de uma empresa são desejáveis, adequadas ou apropriadas dentro de alguns sistemas socialmente construídos de normas, valores, crenças e definiçóes.

Com base nos fundamentos de Freeman e McVea (2001), Hoff (2008) expressa que com a turbulência e aceleraçáo das mudanças no ambiente organizacional, as limitaçóes das abordagens tradicionais de gerenciamento estratégico se tornaram mais evidentes, e assim nota-se que os interesses dos principais Stakeholders, também chamados de Stakeholders chave, podem ser incorporados aos interesses da organização, fazendo então com que os relacionamentos sejam gerenciados de maneira coerente e estratégica para as organizaçóes. 
A Teoria dos Stakeholders contribui também para entender a organização no contexto social, econômico e político no qual está inserida. Por meio dela se faz possível entender a magnitude do compromisso que as organizaçóes possuem com o ambiente ao qual se inserem, em aspectos como economia, responsabilidade legal, ética e filantrópica (SANTOS, 2006).

\subsection{Classificação dos Stakeholders}

Para conciliar os interesses surge a necessidade de classificar os Stakeholders por meio de algum critério (BARBIERI; CAJAZEIRA, 2009). Podem ser decompostos em dois grupos, sendo considerados primários ou secundários, de acordo com a natureza de sua influência sobre a empresa (ALMEIDA, et al., 2018). Desta forma, primários são aqueles sem os quais a empresa não sobreviveria sem a sua constante cooperação. São caracterizados por apresentar um alto nível de interdependência com a empresa (CLARKSON, 1995). Os secundários são aqueles que influenciam ou afetam a empresa, são influenciados ou afetados por ela, porém não estão efetivamente envolvidos em transaçóes e nem são primordiais para a sobrevivência da mesma (CLARKSON, 1995; RIBEIRO; COSTA, 2017). Categorizar os Stakeholders em grupos, primários e secundários, auxilia para que haja uma gestão adequada para lidar com a diversidade de interesses na organização (BARBIERI; CAJAZEIRA, 2009).

A identificação dos Stakeholders em uma organização fica a encargo da percepçáo dos gestores, que precisam identificar as percepçôes de poder, urgência e legitimidade associadas aos relacionamentos gestorstakeholder (MELO; RÉGIS, 2012). Identificadas as percepçóes, direciona-se o grau de importância e qual a prioridade dada a cada Stakeholder, que sáo positivamente relacionados à acumulaçáo dos atributos (poder, urgência e legitimidade) percebidos pelos gestores (MELO; RÉGIS, 2012).

Quadro 1 - Atributos dos Stakeholders

\begin{tabular}{|l|l|}
\hline Atributo & Relaçáo com Stakeholders \\
\hline PODER & $\begin{array}{l}\text { Uma organização/indivíduo tem o poder, na medida em que tem ou pode ter acesso } \\
\text { coercitivo, utilitário ou meios normativos, para impor sua vontade no relacionamento. }\end{array}$ \\
\hline LEGITIMIDADE & $\begin{array}{l}\text { A noção de "legitimidade" refere-se vagamente a estruturas ou comportamentos geralmente } \\
\text { aceitos e esperados socialmente, mas muitas vezes é acoplado implicitamente com o poder, } \\
\text { quando as pessoas tentam avaliar a natureza dos relacionamentos na sociedade. }\end{array}$ \\
\hline URGÊNCIA & $\begin{array}{l}\text { Existe apenas quando estiverem preenchidas duas condiçáes: (1) quando um relacionamento } \\
\text { ou reclamação é de natureza urgente e (2) quando esse relacionamento ou reivindicação é } \\
\text { importante ou crítica para o Stakeholder. Combinada com a legitimidade promove o acesso } \\
\text { aos canais de tomada de decisão, e em combinação com o poder, incentiva a ação unilateral } \\
\text { dos Stakeholders. Em combinaçáo com ambos, desencadeia reconhecimento recíproco e de } \\
\text { açáo entre os Stakeholders e gestores. }\end{array}$ \\
\hline
\end{tabular}

Fonte: Santos, Cavichioli e Zanchet (2016)

Os Stakeholders também podem ser internos, que envolvem a própria organização com seus proprietários, diretores, gerentes e funcionários, e externos, os que se encontram ao redor da organização (ROCHA; GOLDSCHMIDT, 2010). Sendo estes os dois principais grupos de Stakeholders organizacionais, Jones (2010) conceitua Stakeholders Internos como as partes interessadas que estão mais próximas de uma organização e possuem influência mais forte e direta em seus recursos; já Stakeholders Externos são 
aqueles que não são nem proprietários nem funcionários da organização, mas possuem algum interesse ou expectativa com relação a ela.

Diversos pesquisadores agrupam os Stakeholders em duas classificaçóes, internos e externos, onde os Stakeholders internos são compostos por gerentes corporativos e funcionários, e os Stakeholders externos abrangem governo, consumidores, ONGs, comunidades sociais, acionistas, credores, associaçóes industriais, concorrentes e fornecedores (LU; ABEYSEKERA, 2014; QIN, HARRISON; CHEN, 2019).

A Figura 1 apresenta uma representação esquematizada exemplificando as diversas partes interessadas em uma organização. No esquema as setas representam a interação entre as partes, onde as partes interessadas afetam e são afetadas, bem como também influenciam e são influenciadas pelas empresas, essa troca entre ambos é demonstrada por setas de mão dupla (BARBIERI; CAJAZEIRA, 2009).

Cada esfera na Figura 1 pode apresentar subgrupos, onde pode haver a ocorrência de interesses conflitantes entre os mesmos e em relação à empresa. Deve-se considerar que esses grupos não são isolados, uns influenciam aos outros como pode ocorrer de os interesses convergirem em certos momentos. No entanto, vale destacar que os interesses não são estáveis e se alteram ao longo do tempo (BARBIERI; CAJAZEIRA, 2009).

Figura 1 - Organização e seus Stakeholders

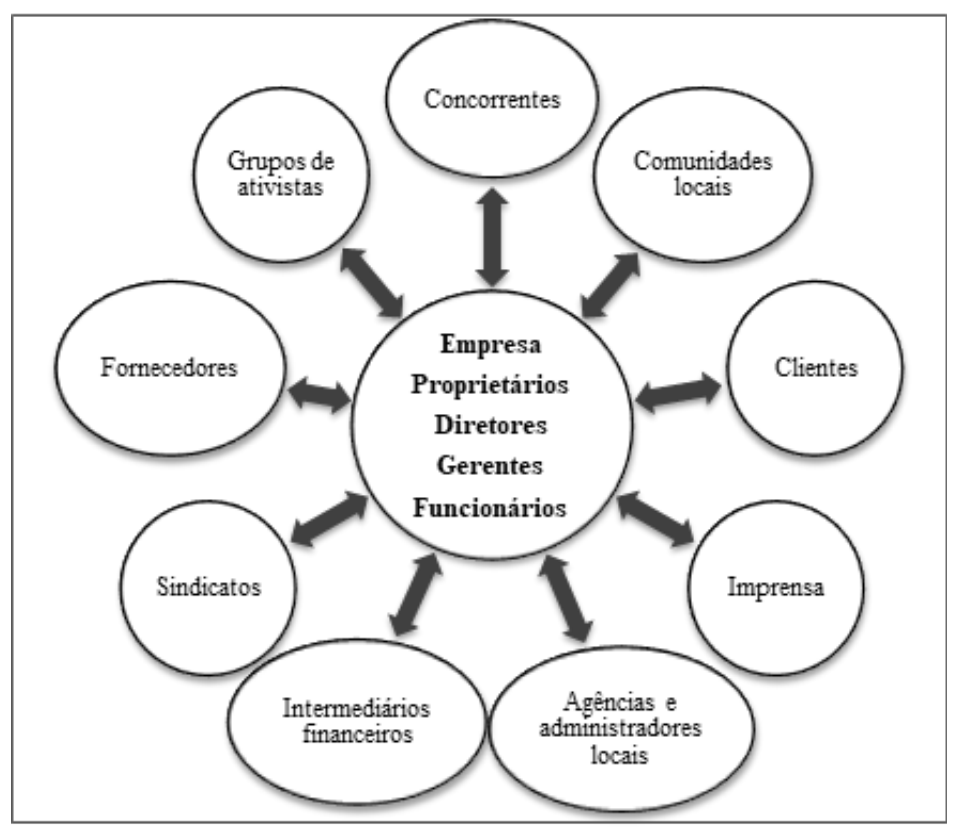

Fonte: Rocha e Goldschmidt (2010)

De acordo com a Figura 1, Rocha e Goldschmidt (2010, p.7) analisam os grupos de Stakeholders e definem:

- Os clientes costumam ser o stakeholder mais estudado pelas empresas, porque, sem ele, estas não existiriam.

- A imprensa é um stakeholder muito importante e que exige cuidados, pois pode interferir no rumo das empresas tanto positiva quando negativamente. 
- As agências e administradores governamentais são os órgãos públicos que regulamentam a atuação das empresas em ramos específicos.

- Os intermediários financeiros são bancos que auxiliam em financiamentos, empréstimos e investimentos de longo prazo.

- Já os sindicatos atuam representando os interesses dos funcionários e dos empregadores, objetivando manter uma boa relação entre eles.

- Os fornecedores representam um importante stakeholder por participar diretamente na cadeia produtiva da empresa, oferecendo produtos e serviços para que a empresa possa operar.

- Os grupos ativistas atuam como representantes dos interesses sociais ante as organizaçóes.

- Os concorrentes são outras empresas que lutam pela mesma participação de mercado.

- As comunidades locais são indivíduos ou empresas que estão ao redor das instalaçóes da organização (ROCHA; GOLDSCHMIDT, 2010, p.7)

As organizaçôes sempre consideram uma relação de mão dupla com seus Stakeholders, pois assim como influenciam são também influenciados, saber gerenciar esta troca pode ser fundamental para adquirir uma vantagem competitiva perante a concorrência (ROCHA; GOLDSCHMIDT, 2010). As relaçóes de interesse existentes entre os grupos se diferem e nem todas possuem o mesmo peso e participação, essas interaçôes se distinguem em razão do poder e da sensibilidade de sua influência (BLANCO-MESA; GILLAFUENTE; MERIGO, 2018). Nesse sentido, podem ocorrer eventos na estrutura de relacionamento, que afetam os resultados organizacionais (BLANCO-MESA; GIL-LAFUENTE; MERIGO, 2018).

Para que se possa separar com segurança os que são daqueles que não são Stakeholders, ao associar os atributos (Quadro 1), se faz a classificação dos Stakeholders. Desse modo, são definidos os grupos e classes, conforme demonstrado na Figura 2 (MITCHELL; AGLE; WOOD, 1997).

No Quadro 1 são apresentados os atributos relacionados aos Stakeholders, e com base neles é possível definir seus grupos e classes, representados na Figura 2.

Figura 2 - Grupos de Classes dos Stakeholders

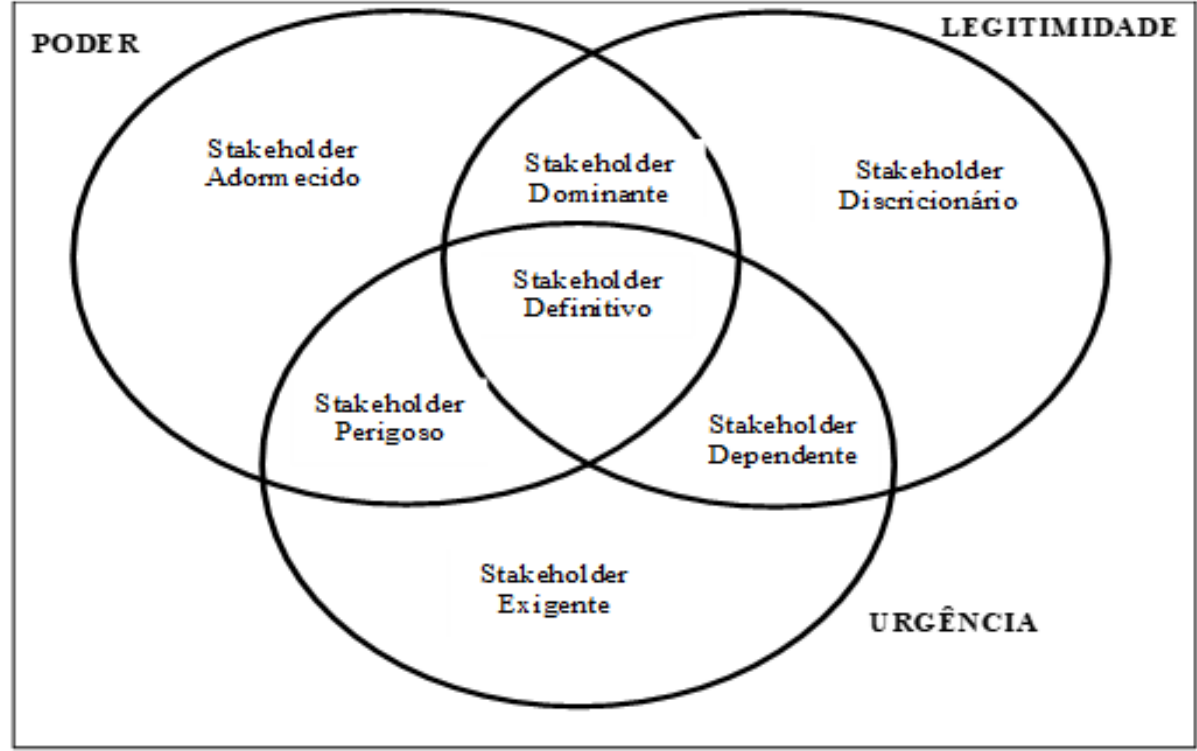

Fonte: Cintra (2013) 
A classificação faz a divisão em tipos, agrupados em três grupos de classes, sendo elas latentes, expectantes e definitivos (MITCHELL; AGLE; WOOD, 1997).

A classe dos latentes compreende os Stakeholders que possuem somente um dos atributos, subdividese em três tipos (ver Adormecido, Exigente e Discricionário, Figura 2). O Stakeholder Adormecido possui somente o atributo poder. Tem como característica o poder de impor sua vontade na empresa. Porém, sem a legitimidade e a urgência, o poder não é usado (MITCHELL; AGLE; WOOD,1997).

O Stakeholder Exigente possui somente o atributo urgência (BAZANINI; RIBEIRO; BAZANINI, 2014). Por não possuir poder nem legitimidade, acaba por ser uma classe importuna aos administradores, uma espécie de "pedra no sapato" (CINTRA, 2013).

O Stakeholder Discricionário possui somente o atributo legitimidade. Por não ter os atributos poder e urgência, acaba por não exercer pressão sobre os administradores para que atendam suas necessidades. No entanto, é o principal público-alvo para receber ajudas filantrópicas (CINTRA, 2013).

A classe dos Stakeholders expectantes é composta por Stakeholders que possuem dois atributos simultaneamente, e também se divide em três tipos (ver Perigoso, Dominante e Dependente, Figura 2). O Stakeholder Perigoso é aquele que possui os atributos poder e urgência. Tendem a ser coercitivos e possivelmente impetuosos, o que os torna literalmente perigosos para a empresa (MITCHELL; AGLE; WOOD, 1997).

O Stakeholder Dominante possui poder e legitimidade. Tem a atenção dos administradores devido à influência adquirida por seus atributos, os interesses destes Stakeholders fazem diferença para a organização (BAZANINI, RIVEIRO, BAZANINI, 2014). O Stakeholder Dependente possui tanto legitimidade quanto urgência. Entretanto, por não possuir poder, acaba dependendo de outros para que tenham suas necessidades atendidas (MITCHELL; AGLE; WOOD, 1997).

Por fim, a classe dos definitivos diz respeito aos Stakeholders definitivos (ver Definitivo, Figura 2). Nesta classe incluem-se os Stakeholders que possuem os três atributos ao mesmo tempo, e nestes casos, os gestores devem dar prioridade as suas reivindicaçóes e atendê-los de imediato (MITCHELL; AGLE; WOOD,1997).

Além de compreender e identificar os grupos de Stakeholders que influenciam a organização, é crucial que a se desenvolva um método para gerenciar os interesses de ambas as partes, que nem sempre se convergem (SANTOS, 2006). Para o autor, a presença de Stakeholders influencia em diversos aspectos nas organizaçóes, especialmente no processo de formaçáo de estratégias.

\section{Metodologia}

Pesquisa descritiva, sob a forma de levantamento, utilizando uma abordagem qualitativa, teve por objetivo identificar quais são os Stakeholders no setor hoteleiro em Foz do Iguaçu-PR, classificá-los e indicar qual a relevância dos mesmos para a atividade.

Os dados para a realização da pesquisa foram coletados por meio de entrevistas semiestruturadas, cujo roteiro foi elaborado com base no modelo de Cintra (2013). A ferramenta utilizada para as entrevistas 
é um roteiro (Anexo A) composto por quatorze questôes abertas e uma breve introdução de caracterização da organização, constituindo-se em cinco blocos, sendo eles:

Bloco I - Trata da caracterização do entrevistado e da instituição;

Bloco II - Identificação dos Stakeholders, suas características, interesses e influências, composto por cinco questóes;

Bloco III - Influências na formulação de estratégias, por parte dos Stakeholders, formado por três perguntas;

Bloco IV - Participação e ação dos Stakeholders locais, apresentado com duas questôes, e;

Bloco V - Identificação da dependência dos Stakeholders, contendo quatro perguntas.

$\mathrm{O}$ universo de pesquisa limita-se as instituiçôes ligadas à atividade hoteleira. Para delimitar o estudo, foram selecionadas como amostra uma instituição de ensino superior que ministra o curso de Hotelaria, o sindicato que representa a atividade na cidade e três empresas categorizadas como hotéis, situadas em diferentes regiōes da cidade. Todas as organizaçóes selecionadas para a amostra encontram-se situadas na cidade de Foz do Iguaçu-PR, onde serão coletados os dados para realização deste estudo.

A população deste estudo é constituída pelos estabelecimentos classificados como hotéis, que operam na cidade de Foz do Iguaçu-PR. De acordo com dados da Prefeitura Municipal de Foz do Iguaçu, conforme levantamento publicado em dezembro de 2014, a quantidade de hotéis na cidade até entáo, totalizava 113 estabelecimentos, sendo esta, a contagem mais recente divulgada pela Secretaria Municipal de Turismo (PMFI, 2014).

A amostra foi selecionada por meio da amostragem não probabilística por conveniência, em que o pesquisador seleciona os elementos aos quais tem acesso, admitindo que estes possam de alguma maneira representar o universo. Esse tipo de amostragem aplica-se a estudos exploratórios ou qualitativos, onde não se requer elevado nível de precisão (PRODANOV; FREITAS, 2013).

Para que as entrevistas fossem feitas, foi realizado um contato prévio com os gestores das organizaçóes para expor a relevância do tema tratado na pesquisa, que agrega também uma autoanálise para a própria empresa. $\mathrm{O}$ empreendimento das entrevistas ocorreu em um intervalo de três meses, em momento conveniente e de acordo com a disponibilidade de cada entrevistado. Os respondentes foram representantes das organizaçóes, de acordo com o grau de envolvimento e afinidade com o tema deste estudo.

As entrevistas foram realizadas pessoalmente e individualmente com os representantes das organizaçóes, gravadas por áudio mediante autorizaçáo, que posteriormente foi transcrito para que houvesse melhor proveito das informaçôes geradas durante o diálogo. Das cinco entrevistas realizadas, apenas uma não foi gravada em áudio, e as informaçôes foram transcritas durante a entrevista. O Quadro 02 apresenta as informaçóes relativas aos entrevistados. 
Revista GESTO: Revista de Gestão Estratégica de Organizaçôes

Santo Ângelo | v. 9 | n. 2 | p. 16-36 | jul./dez. 2021 | DOI: http://dx.doi.org/10.31512/gesto.v9i2.275

Quadro 2 - Informaçóes Relativas aos Entrevistados

\begin{tabular}{|l|l|l|l|l|}
\hline Entrevistado & Formação & Função & Tempo de função & Tempo de empresa \\
\hline $\begin{array}{l}\text { Entrevistado 1 } \\
\text { (representante 1 } \\
\text { dos hotéis) }\end{array}$ & $\begin{array}{l}\text { Graduação em } \\
\text { hotelaria e graduação } \\
\text { em direito }\end{array}$ & $\begin{array}{l}\text { gerente de } \\
\text { operaçóes }\end{array}$ & alguns meses & 3,5 anos \\
\hline $\begin{array}{l}\text { Entrevistado 2 } \\
\text { (representante 2 } \\
\text { dos hotéis) }\end{array}$ & $\begin{array}{l}\text { Graduação em } \\
\text { hotelaria }\end{array}$ & $\begin{array}{l}08 \text { anos (inclui } \\
\text { tempo fora da } \\
\text { empresa) }\end{array}$ & 05 anos \\
\hline $\begin{array}{l}\text { Entrevistado 3 } \\
\text { (representante 3 } \\
\text { dos hotéis) }\end{array}$ & $\begin{array}{l}\text { Cursando ensino } \\
\text { superior (não } \\
\text { informado qual) }\end{array}$ & chefe de reservas & 03 meses & 08 meses \\
\hline $\begin{array}{l}\text { Entrevistado 4 } \\
\text { (representante do } \\
\text { corpo docente) }\end{array}$ & $\begin{array}{l}\text { Graduação em } \\
\text { turismo e hotelaria } \\
\text { e pós-doutorado em } \\
\text { gestão de negócios }\end{array}$ & $\begin{array}{l}\text { Professor do curso } \\
\text { de Hotelaria }\end{array}$ & 12 anos & 12 anos \\
\hline $\begin{array}{l}\text { Entrevistado 5 } \\
\text { (representante do } \\
\text { sindicato do setor } \\
\text { hoteleiro) }\end{array}$ & $\begin{array}{l}\text { Graduação em } \\
\text { jornalismo }\end{array}$ & Diretor executivo & $\begin{array}{l}35 \text { anos (inclui } \\
\text { tempo fora da } \\
\text { empresa) }\end{array}$ & 03 anos \\
\hline
\end{tabular}

Fonte: Elaborado pelos autores

Após a realização das entrevistas, as informações coletadas neste procedimento foram examinadas buscando identificar os dados, a fim de caracterizar e categorizá-los de acordo com a teoria proposta, para que assim fosse dado seguimento ao processo de análise.

\section{Resultados e Discussões}

\section{1 Identificação dos Stakeholders}

No momento das entrevistas, foi feita aos entrevistados uma explicação sobre o assunto Stakeholders e foram citados alguns exemplos, a fim de propiciar um melhor entendimento para os mesmos a respeito do tema abordado.

A identificação dos Stakeholders teve por base perguntas em que os entrevistados tiveram que identificar os Stakeholders atuantes no setor e, ordená-los por hierarquia de importância, justificando suas opçóes.

Inicialmente, foram entrevistados representantes de três hotéis na cidade de Foz do Iguaçu-PR. Por meio das entrevistas com os representantes foi possível identificar seis Stakeholders relevantes do setor, elencados no Quadro 4.

Os Stakeholders clientes, funcionários e fornecedores foram mencionados pelos três entrevistados como relevantes para o setor. Conforme evidenciado por eles, os clientes são o principal foco da organização, são cruciais para o funcionamento da empresa, e praticamente todas as açóes empreendidas pela organização são em função da fidelização dos mesmos, como evidenciado pelo Entrevistado 2 que 
afirma que "todas, ou praticamente todas as nossas ações são para fidelização dos clientes [...] então a gente faz tudo voltado para o bem-estar do cliente". De acordo com a percepção dos entrevistados ocorre uma colaboraçáo mútua entre empresa e clientela, neste ponto o Entrevistado 3 destaca que a organizaçáo "pega a demanda deles, vê o que eles estáo precisando e vai evoluindo, a gente vai acompanhando o mercado, vai evoluindo por causa disso".

O grupo funcionários foi evidenciado como importante também pelos entrevistados, pois são considerados de suma importância para o funcionamento das empresas. Um dos entrevistados ressaltou a questão da autonomia dos funcionários dentro da organizaçáo, a liberdade de poder conversar com os clientes, tentar resolver contratempos, sendo importante manter um bom clima organizacional, benéfico para ambas as partes. O Entrevistado 2 enfatiza que a organização em que atua "consegue manter um ambiente bom para os colaboradores. Não é uma coisa bem engessada. [...] Tanto que, a gente não tem tanta rotatividade de funcionários".

Outro Stakeholder apontado é o conjunto de fornecedores. Conforme destacado pelo Entrevistado 1 , os fornecedores são responsáveis pelo provimento de "insumos e materiais para que o hotel transforme em produtos e serviços". Para o Entrevistado 3 "os fornecedores têm que fornecer material para os funcionários conseguirem trabalhar".

Por meio das entrevistas com estes representantes foram identificados também os Stakeholders proprietários, parceiros comerciais e o Sindicato de Hotéis, Restaurantes, Bares e Similares de Foz do Iguaçu - SINDHOTEIS. Segundo a perspectiva dos entrevistados, fica a encargo dos proprietários o atendimento aos interesses de clientes e funcionários, além de serem os principais responsáveis pelas decisôes na organização.

Os parceiros comerciais estão ligados ao atingimento de metas e objetivos da organização. $\mathrm{O}$ SINDHOTEIS fornece assistência em alguns aspectos, oferece cursos para o setor que pode proporcionar algumas vantagens para as instituiçôes, além da regulamentação das relaçôes trabalhistas do setor.

Quanto à ordem de importância, além de identificarem alguns Stakeholders distintos, houve divergência na ordem de hierarquia percebida pelos representantes dos hotéis. Os Entrevistados 2 e 3 fizeram uma classificação similar dos Stakeholders, já o Entrevistado 1 os ordenou de forma distinta. A ordem de importância apresentada pelos entrevistados representantes dos hotéis é expressa no Quadro 3, em ordem hierárquica decrescente, do topo para a base.

Quadro 3 - Classificação hierárquica dos Stakeholders pelos Hotéis

\begin{tabular}{|c|c|c|}
\hline Entrevistado 1 & Entrevistado 2 & Entrevistado 3 \\
\hline Clientes & Clientes & Clientes \\
\hline Funcionários & Proprietários & Proprietários \\
\hline Fornecedores & Funcionários & Funcionários \\
\hline Parceiros Comerciais & Fornecedores & Fornecedores \\
\hline & SINDHOTEIS & \\
\hline
\end{tabular}

Fonte: Dados da pesquisa 
Por meio da entrevista com o representante do corpo docente de uma instituição de ensino superior que ministra o curso de Hotelaria na cidade, foi possível identificar oito Stakeholders do ramo (Quadro 4), sendo eles: acionistas, clientes, comunidade, concorrentes, fornecedores, funcionários, governo e meio ambiente. Apesar de identificar os Stakeholders do setor, o entrevistado ressalta que não poderia ordenálos por grau de importância, pois essa hierarquia varia de organização para organizaçáo, por conta dos próprios objetivos das empresas, do meio ambiente ao quais as mesmas se inserem, dentre outros fatores que podem afetar a importância dada a cada Stakeholder. Sendo assim, ele como observador externo náo estaria apto a classificá-los por ordem de importância, tendo em vista que cada Stakeholder pode possuir relevância em maior ou menor grau dependendo da conjuntura.

Por fim, em entrevista ao representante do Sindicato que representa o setor hoteleiro, foram identificados dezesseis grupos de Stakeholders para o ramo, apresentados no Quadro 4. De acordo com o entrevistado, um hotel pode ser visto como uma "cidade", ressalta que o hotel "tem todos os mecanismos de funcionamento de uma cidade. Ele tem segurança, ele tem alimentação, ele tem transporte, ele tem todo tipo de fornecimento". Sendo assim, todos os Stakeholders são vitais para o funcionamento de um hotel, pois para o entrevistado nenhum meio de hospedagem poderia funcionar com algum de seus Stakeholders em desequilíbrio. O entrevistado ainda exemplifica da seguinte forma: "eu posso ter um hotel muito bonito, com tudo funcionando e não ter hóspedes. Ou, posso ter um hotel cheio de hóspedes e cheio de problemas" evidenciando a importância da sintonia entre os Stakeholders.

Quadro 4 - Identificação dos Stakeholders

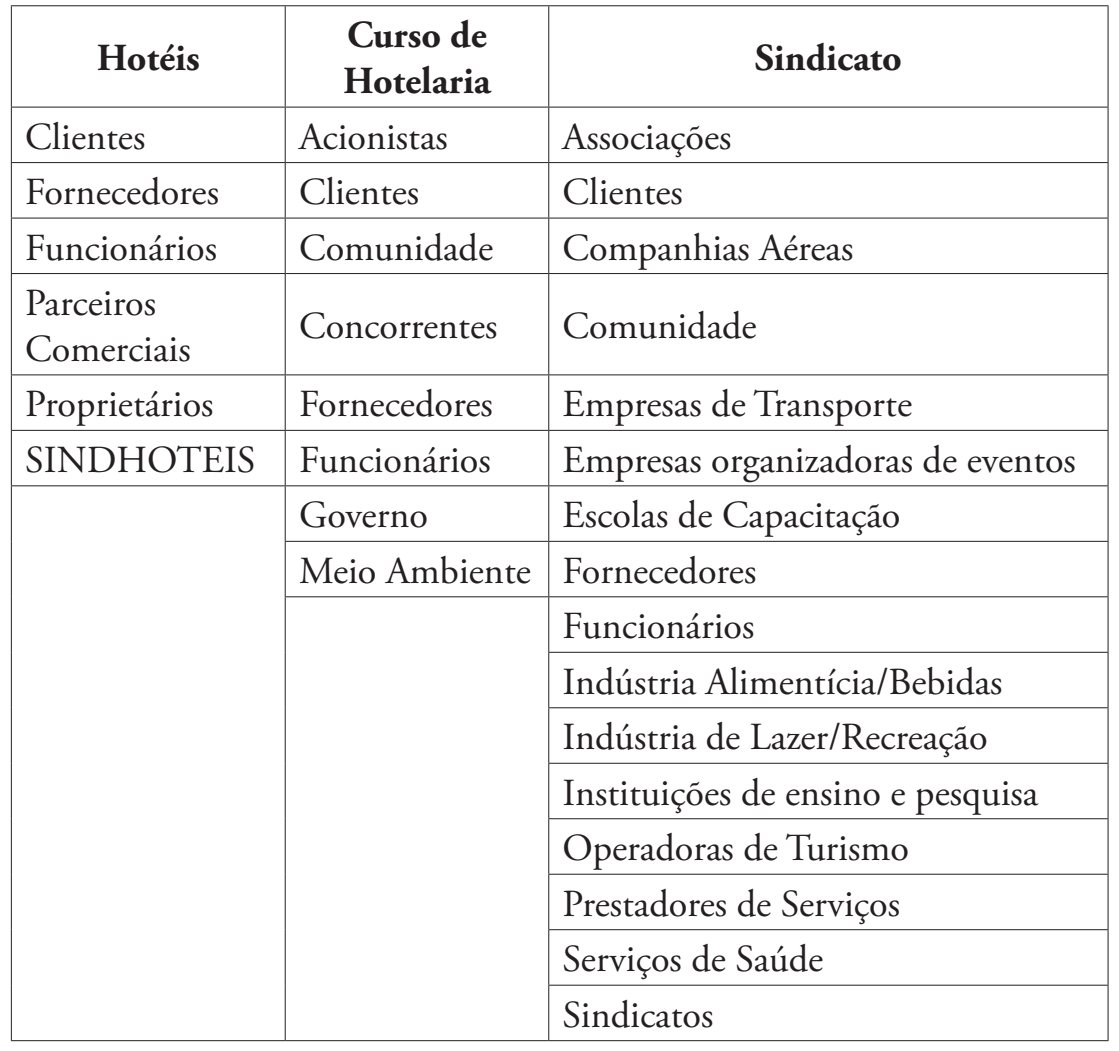

Fonte: Dados da pesquisa 
O Quadro 4 apresenta todos os Stakeholders identificados pelos entrevistados representantes das organizaçóes, listados em ordem alfabética devido as diferenças de percepção dos entrevistados com relação a classificação por ordem de importância.

Em análise ao conjunto de Stakeholders identificados por todos os entrevistados, é possível notar que a definição de parceiros comerciais expressada pelo Entrevistado 1, representando um dos hotéis, vai ao encontro com alguns dos Stakeholders identificados pelo Entrevistado 5, representante do sindicato. De acordo com o Entrevistado 1, parceiros comerciais "são agências de viagens, operadores de viagens, receptivos locais, outros hotéis, guias de turismo", sendo assim, se assemelham a alguns dos citados pelo Entrevistado 5, tais como operadoras de turismo, prestadores de serviços, companhias aéreas e empresas de transporte. O Entrevistado 1 também menciona "outros hotéis" como parceiros comerciais, que seria o equivalente a "concorrentes" na visão do Entrevistado 4, representante da instituição de ensino.

\subsection{Características e Categorizaçâo Dos Stakeholders}

Concomitante ao processo de identificação dos Stakeholders, empreendeu-se também a atribuição das características aos mesmos. Ou seja, a verificaçáo de quais atributos os Stakeholders possuem, para posteriormente definir seus grupos e classes. Os atributos foram relacionados aos Stakeholders pelos próprios entrevistados, mediante uma prévia explicação da correlação exigida para que o atributo seja associado ao Stakeholder.

Os atributos associados aos Stakeholders identificados pelos representantes dos hotéis, são evidenciados no Quadro 5, de acordo com o entendimento dos entrevistados.

Quadro 5 - Atributos dos Stakeholders Identificados pelos Hotéis

\begin{tabular}{|l|c|c|c|}
\hline \multirow{2}{*}{ STAKEHOLDERS } & \multicolumn{3}{|c|}{ ATRIBUTOS } \\
\cline { 2 - 4 } & PODER & LEGITIMIDADE & URGÊNCIA \\
\hline Clientes & $\mathrm{X}$ & $\mathrm{X}$ & $\mathrm{X}$ \\
\hline Fornecedores & & $\mathrm{X}$ & $\mathrm{X}$ \\
\hline Funcionários & & $\mathrm{X}$ & $\mathrm{X}$ \\
\hline Parceiros Comerciais & $\mathrm{X}$ & $\mathrm{X}$ & $\mathrm{X}$ \\
\hline Proprietários & $\mathrm{X}$ & $\mathrm{X}$ & \\
\hline SINDHOTEIS & & $\mathrm{X}$ & \\
\hline
\end{tabular}

Fonte: Dados da pesquisa

Com base nas características atribuídas aos seis Stakeholders listados no Quadro 5, na classe latentes foi identificado apenas um Stakeholder como discricionário, por possuir apenas o atributo legitimidade, sendo ele o SINDHOTEIS. Dentre os Stakeholders identificados pelos hotéis, nenhum foi classificado como adormecido ou exigente.

$\mathrm{Na}$ classe dos expectantes, os proprietários foram considerados pertencentes ao grupo dominante, por possuírem os atributos poder e legitimidade. No grupo dependente, se enquadraram os fornecedores e funcionários, por possuírem os atributos legitimidade e urgência. Não foram identificados Stakeholders para o grupo perigoso. 
Referente ao grupo definitivo, foram considerados dois Stakeholders pertencentes ao grupo, sendo eles clientes e parceiros comerciais, que se identificou possuírem os três atributos, poder, legitimidade e urgência. A representação da classificação nos grupos, dos Stakeholders citados, é evidenciada na Figura 3.

Figura 3 - Grupos de Classes dos Stakeholders Identificados pelos Hotéis

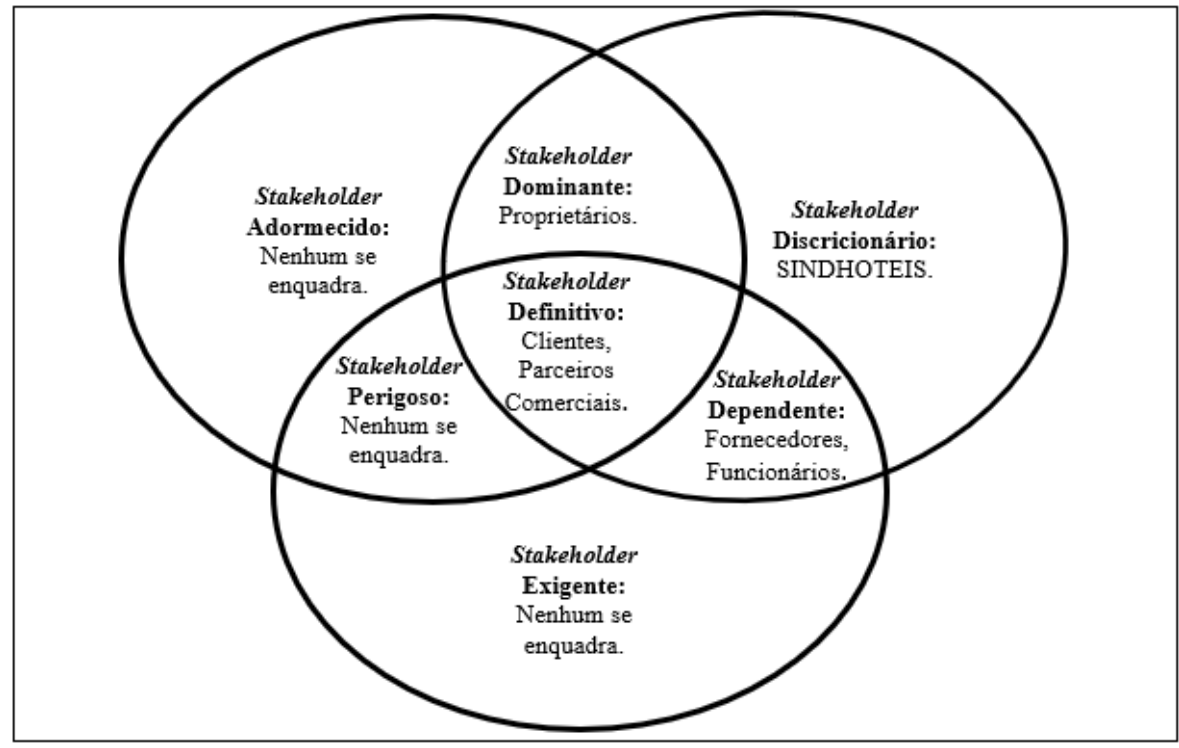

Fonte: Dados da pesquisa

No que se refere aos Stakeholders identificados pelo representante da instituição de ensino, para o entrevistado os atributos poder e legitimidade se aplicam a todos os Stakeholders mencionados por ele. No entanto irá depender da relação social entre as partes envolvidas. As relações sociais entre organização e Stakeholders se dividem nos ambientes interno e externo, e em ambos os ambientes se subdivide pelas dimensões ambiental, sociocultural e econômica (SOUZA, 2014).

Com base na afirmação do entrevistado, todos os Stakeholders por ele citados se enquadrariam no grupo de Stakeholders dominantes, por possuírem os atributos poder e legitimidade, e o que poderia alterar essa classificação seria a relação social entre as partes.

Sob a ótica do representante do Sindicato, todos os Stakeholders possuem os três atributos em potencial, porém a atribuição dos mesmos estaria ligada ao momento em evidência, como exemplo, o mesmo citou o período do café da manhã em um hotel, onde os Stakeholders mais importantes seriam os essenciais para que não haja lapsos na ocasião em questão. Sendo assim, os atributos e o grau de importância seriam dados por cada organização de acordo com as circunstâncias.

\section{Considerações finais}

O desenvolvimento do presente estudo teve como objetivo identificar os Stakeholders significativos na atuação do setor hoteleiro na cidade de Foz do Iguaçu-PR, e classificá-los de acordo com sua relevância para a atividade.

Conforme os resultados evidenciados na pesquisa, foram identificados ao todo vinte e dois Stakeholders do setor hoteleiro na cidade, sendo eles: acionistas, associaçóes, clientes, companhias 
aéreas, comunidade, concorrentes, empresas de transporte, empresas organizadoras de eventos, escolas de capacitação, fornecedores, funcionários, governo, indústria alimentícia/bebidas, indústria de lazer/ recreação, instituiçóes de ensino e pesquisa, meio ambiente, operadoras de turismo, parceiros comerciais, prestadores de serviços, proprietários, serviços de saúde e o Sindicato de Hotéis, Restaurantes, Bares e Similares de Foz do Iguaçu - SINDHOTEIS.

Quanto a classificação dos Stakeholders, foram classificados apenas os seis Stakeholders identificados pelos representantes dos hotéis, que atribuíram as características aos mesmos de acordo com o que presenciam nas atividades das organizaçóes que representaram. De acordo com essa análise, foram identificados nas classes: um Stakeholder discricionário, um Stakeholder dominante, dois Stakeholders dependentes e dois Stakeholders definitivos. Nas classes adormecido, exigente e perigoso não foram enquadrados nenhum Stakeholder.

Ainda sobre a classificação, os Stakeholders identificados por meio das entrevistas na instituição de ensino e no sindicato, foram julgados sob uma perspectiva diferente pelos entrevistados. Conforme entendimento, para o representante da instituição de ensino, os atributos legitimidade e poder se aplicam a todos os Stakeholders mencionados, o que os enquadra na classe Stakeholder dominante. Contudo esta caracterização dos Stakeholders fica à mercê das relaçóes sociais existentes entre as partes envolvidas. Para o ator vinculado ao sindicato, todos os Stakeholders têm potencialmente os três atributos, e o fator determinante para atribuí-los é o momento que estiver em análise. Neste sentido, ao analisar as informaçóes passadas pelos entrevistados, verifica-se que a fiel retratação da caracterização e classificação dos Stakeholders se dá pelas próprias organizaçóes, de acordo com o contexto vivenciado por cada uma delas.

Vale ressaltar também que, se levada em consideração a localização das empresas classificadas como hotéis e resorts que participaram desta pesquisa, é possível constatar diferenças de objetivos das organizações. Tendo em vista que as mesmas estão instaladas em zonas de mercado distintas, onde o principal atrativo varia entre comércio e turismo, tal fator pode influenciar diretamente na relação com os Stakeholders. O grau de importância dado a cada um dos Stakeholders pode ser diversificado, de acordo o que é almejado por cada empresa.

Dado que o trabalho se limitou ao setor hoteleiro da cidade de Foz do Iguaçu-PR, não é possível generalizar os resultados obtidos, tampouco estendê-los para outras realidades.

Este trabalho apresentou limitação com relação a amostra estudada. As empresas hoteleiras foram selecionadas por conveniência e de acordo com a disponibilidade dos representantes para participar da pesquisa, além da dependência de autorização, onde em alguns casos não houve permissão por conta de regimento interno das organizaçóes. Sendo assim, considerando a proporção da amostra para a população, não se pode afirmar com convicção e exatidáo, que os resultados obtidos condizem com a realidade de todos os hotéis da cidade.

Outra limitação considerável do presente estudo diz respeito a ausência de classificação hierárquica dos Stakeholders, identificados por parte dos entrevistados representantes da instituição de ensino e do sindicato, sob a justificativa de que não seria possível afirmar com exatidão essa ordem como observador externo, pois cada empresa possui suas particularidades, que influenciam no grau de importância a se considerar para cada Stakeholder. 
Como sugestão para trabalhos futuros, este estudo poderia dar origem a um aprofundamento mais detalhado das relaçóes entre os Stakeholders, a fim de se ampliar o entendimento da relação de interesse existente entre os mesmos.

\section{Referências}

ABIH - Associação Brasileira da Indústria de Hotéis. Apresentação. Disponível em: <http://abih.com. br/apresentacao/>. Acesso em 18 de novembro de 2019.

ALMEIDA, Karla Katiuscia Nobrega; SOUZA, Fábia Jaiany Viana de; PAIVA, Simone Bastos; CÂMARA, Renata Paes de Barros. Práticas de Comunicação e de Compartilhamento de Informações com Clientes e Fornecedores nos Relatórios de Sustentabilidade por Companhias Elétricas. Revista Evidenciação Contábil e Finanças, João Pessoa, v. 6, n. 2, p. 14-35, mai/ago. 2018. https://dialnet. unirioja.es/servlet/articulo?codigo $=6636738$

BARBIERI, José Carlos; CAJAZEIRA, Jorge Emanuel Reis. Responsabilidade social empresarial e empresa sustentável: da teoria à prática. São Paulo: Saraiva, 2009.

BAZANINI, Roberto; RIBEIRO, Hewdy Lobo; BAZANINI, Homero Leoni. Estratégia dos negócios: obstáculos encontrados para a consolidação da TV Digital no Brasil e seus impactos na cadeia produtiva eletroeletrônica na perspectiva da teoria dos stakeholders. Revista de Negócios. Blumenau, v. 19, n. 1, p. 70-93, jan/mar. 2014.

BEUREN, Ilse Maria (Org.) Como Elaborar Trabalhos Monográficos em Contabilidade: Teoria e Prática. $3^{a}$ ed. Sáo Paulo: Atlas, 2008. (SÓ REFERENCIADA)

BLANCO-MESA, Fabio; GIL-LAFUENTE, Anna; MERIGO, José. Subjective stakeholder dynamics relationships treatment: a methodological approach using fuzzy decision-making. Computational and Mathematical Organization Theory, [s. l.], v. 24, n. 4, p. 441-472, out. 2018. https://link.springer.com/ article/10.1007/s10588-018-09284-z

CAMPOS, Taiane Las Casas. Políticas para Stakeholders: um Objetivo ou uma Estratégia Organizacional. Revista de Administração Contemporânea, Curitiba, v. 10, n. 4, p. 111-130, out./dez. 2006. https://doi.org/10.1590/S1415-65552006000400006

CINTRA, Renato Fabiano. Stakeholders e setor turístico brasileiro: uma investigação na cidade de Londrina-PR. 2013. 180 f. Dissertação (Mestrado em Administração) - Gestão de Organizaçóes, Universidade Estadual de Londrina, Londrina, 2013.

CLARKSON, Max E. A stakeholder framework for analyzing and evaluating corporate social performance. Academy of management review, v. 20, n. 1, p. 92-117, 1995. https://doi.org/10.5465/ amr.1995.9503271994

COSTA, Benny Kramer; VIEIRA, Saulo Fabiano Amâncio; BOAVENTURA, João Maurício Gama; AÑEZ, Miguel Eduardo Moreno. A influência dos stakeholders na estratégia de órgãos públicos: o caso 
da Diretoria de Turismo de Guarulhos/SP. Revista Gestão Organizacional, Chapecó, v. 5, n. 1, p. 28-40, jan/jun. 2012.

DONALDSON, Thomas; PRESTON, Lee E. The stakeholder theory of the corporation: Concepts, evidence, and implications. Academy of management Review, v. 20, n. 1, p. 65-91, 1995. https://doi. org/10.5465/amr.1995.9503271992

FABRIS, Juliana; FISCHER, Augusto; SEHEM, Simone. A Cidade do Idoso à luz da Teoria dos Stakeholders. Reuna, Belo Horizonte, v. 20, n. 1, p. 5-24, jan/mar. 2015. https://revistas.una.br/reuna/ article/view/637

FREEMAN, R. Edward; MCVEA, John. A stakeholder approach to strategic management. The Blackwell handbook of strategic management, p. 189-207, 2001. https://papers.ssrn.com/sol3/papers. cfm?abstract_id=263511

GATTAI, Silvia; SIQUEIRA, Douglas Murilo; FISCHER, Rosa Maria. Compreender os interesses e relaçóes - estudo de projeto de implantação de incubadora de empreendimentos solidários. Pensamento \& Realidade, [s. l.], v.28, n. 3, p. 1-24, 2013. https://revistas.pucsp.br/pensamentorealidade/article/ view/17569

GOMES, Ricardo Corrêa. Stakeholder Management in the Local Government Decision-Making Area: Evidences from a Decision-Making Area: Evidences from a Triangulation Study with the English Local Triangulation Study with the English Local Government. Revista de Administração Contemporânea, [s. l.], v. 10, Edição Especial, p. 77-98, 2006. https://doi.org/10.1590/S1415-65552006000500005

GOMES, Sônia Maria da Silva; ALMEIDA, Sidmar Roberto Vieira. Relação entre o Disclosure de Riscos Climáticos e o Retorno Anormal das Empresas Brasileiras. Revista Universo Contábil, Blumenau, v. 13, n. 2, p. 149-165, abr./jun. 2017. DOI:10.4270/RUC.2017213

HOFF, DEBORA Nayar. A construção do desenvolvimento sustentável através das relaçóes entre as organizaçóes e seus stakeholders: A proposição de uma estrutura analítica. 2008. 425 f. Tese (Doutorado em Agronegócios) - Programa de Pós-Graduação em Agronegócios, Universidade Federal do Rio Grande do Sul, Porto Alegre, 2008.

HOURNEAUX JUNIOR, Flavio; SIQUEIRA, João Paulo Lara de; TELLES, Renato.; CORRÊA, Hamilton Luiz. Análise dos stakeholders das empresas industriais do estado de São Paulo. Revista de Administração, São Paulo, v. 49, n. 1, p 158-170, jan./fev./mar. 2014. https://doi.org/10.5700/ rausp1138

JONES, Gareth R. Teoria das organizações. 6a ed. São Paulo: Pearson, 2010.

LU, Yingjun; ABEYSEKERA, Indra. Stakeholders' power, corporate characteristics, and social and environmental disclosure: evidence from China. Journal of cleaner production, v. 64, p. 426-436, 2014. https://doi.org/10.1016/j.jclepro.2013.10.005

LUGOBONI, Leonardo Fabris; GOTO, Melissa Midori Martinho. Stakeholders Presentes nas Missões Organizacionais: Uma Análise por Setor e Origem de Controle Acionário. Revista de Administração da UFSM, Santa Maria, v. 11, n. 3, p. 615-636, 2018. 
MARTINS, Vinicius Abilio; ENSSLIN, Sandra Rolim. Analysis of the use of performance evaluation theoretical foundations in empirical studies: an investigation in publications aiming at future research questions. International Journal of Business Innovation and Research, v. 23, n. 1, p. 41-63, 2020. https://doi.org/10.1504/IJBIR.2020.109323

MARTINS, Vinicius Abilio; ENSSLIN, Sandra Rolim; DUTRA, Ademar. Avaliação de Desempenho Organizacional: trajetória das pesquisas internacionais por meio de paradigmas e teorias. Cuad. Contab., Bogotá, v. 19, n. 47, p. 94-116, June 2018 . http://dx.doi.org/10.11144/javeriana.cc19-47.pado.

MATOS, Lucas dos Santos; VALMORBIDA, Sandra Mara Iesbik; MARTINS, Vinicius Abilio; ENSSLIN, Sandra Rolim; Development of performance evaluation theme: A systematic analysis of the literature. Contextus: Revista Contemporânea de economia e gestão, v. 17, n. 2, p. 63-97, 2019.

MELO, Paulo Thiago Bezerra; RÉGIS, Helder Pontes. Stakeholders Relevantes no Perfil dos Gestores dos Pontos de Cultura no Grande Recife. Revista Organizaçóes em Contexto, São Bernardo do Campo, v. 8, n. 15, p. 109-136, jan./jun. 2012. https://doi.org/10.15603/1982-8756/roc.v8n15p109-136

MITCHELL, Ronald K.; AGLE, Bradley R.; WOOD, Donna J. Toward a theory of stakeholder identification and salience: Defining the principle of who and what really counts.Academy of management review, v. 22, n. 4, p. 853-886, 1997. https://doi.org/10.5465/amr.1997.9711022105

MEHERISHI, Lavanya; NARAYANA, Sushmita A.; RANJANI, K.S. Sustainable packaging for supply chain management in the circular economy: A review. Journal of Cleaner Production, [s. l.], v. 237, nov. 2019. https://doi.org/10.1016/j.jclepro.2019.07.057

NACITI, Valeria. Corporate governance and board of directors: The effect of a board composition on firm sustainability performance. Journal of Cleaner Production, [s. l.], v. 237, nov. 2019. https://doi. org/10.1016/j.jclepro.2019.117727

ORTEGA, Rubens Paulino; MELO, Pedro Lucas de Resende; BOAVENTURA, João Maurício Gama.; MASCENA, Keysa Manuela Cunha de. Atendimento dos Interesses do Stakeholder Franqueado e sua Relação com o Desempenho Financeiro em Redes de Franquias. Revista de Administração da UFSM, Santa Maria, v. 9, n. Ed. Especial, p. 24-38, dez. 2016. https://www.redalyc.org/articulo. oa?id=273449349003

PMFI - Prefeitura Municipal de Foz Do Iguaçu (2019a). A Cidade. Disponível em: <http://www.pmfi. pr.gov.br/turismo/?idMenu=722>. Acesso em 03 de outubro de 2019.

PMFI - Prefeitura Municipal de Foz Do Iguaçu (2019b). Atrativos Turísticos. Disponível em: <http:// www.pmfi.pr.gov.br/turismo/?idMenu=723>. Acesso em 03 de outubro de 2019.

PMFI - Prefeitura Municipal de Foz Do Iguaçu. Inventário da Oferta Turística de Foz do Iguaçu 2014. Disponível em: <http://www.pmfi.pr.gov.br/ArquivosDB?idMidia=75475>. Acesso em 03 de outubro de 2019.

PRODANOV, Cleber Cristiano; FREITAS, Ernani Cesar. Metodologia do trabalho científico: métodos e técnicas da pesquisa e do trabalho acadêmico. 2a ed. Novo Hamburgo: Feevale, 2013. 
QIN, Yan; HARRISON, Julie; CHEN, Li. A framework for the practice of corporate environmental responsibility in China. Journal of Cleaner Production, [s. l.], v. 235, p. 426-452, out. 2019. https:// doi.org/10.1016/j.jclepro.2019.06.245

RIBEIRO, Henrique César Melo. Influência da Governança Corporativa nos Stakeholders das Entidades Esportivas. Revista Pretexto, Belo Horizonte, v. 17, n. 3, p. 40-56, jul./set. 2016. https://doi. org/10.21714/pretexto.v17i3.3124

RIBEIRO, Henrique César Melo; COSTA, Benny Cramer. Influência dos Stakeholders na gestão e no controle das organizaçóes esportivas. Revista Ciências Administrativas, Fortaleza, v. 23, n. 1, p. 42-69, jan./abr. 2017. https://www.redalyc.org/pdf/4756/475655252003.pdf

ROCHA, Thelma; GOLDSCHMIDT, Andrea. Gestão dos Stakeholders. São Paulo: Saraiva, 2010.

SANTOS, Jéferson Weber. A influência dos Stakeholders na estratégia: um estudo de caso em uma organização do terceiro setor. 2006. 130 f. Dissertação (Mestrado em Administração) - Mestrado em Administração e Negócios, Pontifícia Universidade Católica do Rio Grande do Sul, Porto Alegre, 2006.

SANTOS, Keila Priscila; CAVICHIOLI, Denize; ZANCHET, Aládio. Identificação e caracterização dos stakeholders do ramo alimentício: um estudo de caso na cidade de Cascavel-PR. In: Congresso de Iniciação Científica em Contabilidade da UFRGS, 1., 2016, Porto Alegre.

SCHEMBRI, Joe; TANG, Yee Kwan., FLETCHER, Margaret., \& DIMITRATOS, Pavlos. How do European trade promotion organizations manage their stakeholders? International Business Review, [s. l.], v. 28 , n. 6, dez. 2019.

SERAFIM, Maurício Custódio; ALPERSTEDT, Graziela Dias. As organizaçóes religiosas e suas relaçóes: Uma análise a partir da teoria dos stakeholders. Revista de Negócios, Blumenau, v. 17, n. 2, p. 21-40, abr./jun. 2012.

SOUZA, Claudio Alexandre. Territorialidade nas açôes de responsabilidade social empresarial dos resorts do Brasil. 2014. 375 f. Tese (Doutorado em Geografia) - Curso de Pós-Graduação em Geografia, Universidade Federal do Paraná, Curitiba, 2014.

TEIXEIRA, Maria Luisa Mendes; MAZZON, José Afonso. Orientação Ética quanto à Mudança Social Envolvendo Stakeholders. Revista de Administração Mackenzie, São Paulo, v. 1, n. 1, p. 51-65, 2000.

WANG, Bin. Executives' Educational Level, Corporate Social Responsibility and "De-noising” Financial Performance-Empirical Data from Chinese Listed Companies Disclosing Social Responsibility Report. Educational Sciences-Theory \& Practice, v. 18, n. 6, p. 3662-3680, dez. 2018. https://jestp. $\mathrm{com} /$ jestpcom/index.php/estp/article/view/154

WILLIAMSOM, Oliver E. Markets and hierarchies: some elementary considerations. The American economic review, v. 63, n. 2, p. 316-325, 1973. 